\title{
A Study on the Language Features of Celebrities' Microblogs from the Perspective of Register
}

\author{
Qixia Liang \\ Shanxi Normal University, China
}

\begin{abstract}
As a new way of communication, people's verbal communication is influenced by Sina microblog which play a significant role in our daily life. The celebrities' microblogs, with powerful celebrity effect, have received lots of attentions and influences in Sina microblog. Register is a kind of language variety used in a particular situation. Because of the particularity of celebrities' profession, the domain variables used by their microblogs are distinguished from the domain variables of the real world. Therefore, in order to enable people to understand their words and treat them in rational ways from multiple angles and perspectives, this research will analyze the celebrities' microblogs from the perspective of three variables of the Register and explore their language characteristics.
\end{abstract}

Index Terms-Register, Celebrities' microblogs, Characteristics of language, Three variables of Register

\section{INTRODUCTION}

Sina microblog is a social website that provides microblogging services. It is currently the largest, most complete and most well-known microblogging website in China. Users can write what they see, hear, and think into a sentence, or post some pictures and share them to their friends anytime, anywhere via computer or mobile phone, and the users can also follow their friends and get the information instantly posted by their friends. In Sina microblog, celebrities have received lots of attention and influenced many people. Every day, tens of thousands of the celebrities' microblogs and comments are posted on the Internet that had imperceptible influence on public verbal communication. Celebrities' microblog language is not only a special language phenomenon, but also a social and cultural phenomenon. Therefore, this research aims to use the Register Theory to analyze some celebrities' microblogs from the perspectives of the field of discourse, the tenor of discourse, and the mode of discourse to explore the characteristics of the mentioned celebrities' microblogs, so that the celebrities' microblogs can be applied to play its positive energy communication effect. Only in this way can people understand their real meanings and have an acceptable value.

This research consists of five parts. Firstly, the research will introduce the background and significance of the research. Secondly, the research will review current research status regarding of Register and celebrities' microblogs. Thirdly, the research will introduce the three variables of Register. And fourthly, the research will analyze the celebrities' microblogs from the three variables of the Register. Finally, a brief summary of this research will be concluded.

\section{LITERATURE REVIEW}

Register Theory has been studied for nearly 30 years in China. Hu Zhuanglin and Zhu Yongsheng, while introducing Systemic functional linguistics, made important contributions to the induction and summarization of Register theory, and also promoted the development of Register theory. In recent years, most of the domestic researches on Register theory are about verbal humor, translation and teaching, while the language of celebrities' microblogs, as a special language, is rarely studied from the Register Theory.

Zheng Songxiao (2016), Sun Yingping (2019) uses the Register Theory to analyze the verbal humor in The Big Bang Theory quantitatively. Wang Chaojing (2017) conducts an in-depth study of the humor in Friends from the three variables of the Register, and interprets its diverse humor.

Some scholars also use the Register Theory to analyze subtitle translation. Wang Yingjie (2017) uses the three elements of the Register domain to construct a translation quality assessment model, and he uses it to evaluate the quality of the translation of the US version of Empresses in the Palace. Li Junfeng (2017) evaluates the original subtitle translation of The Grandmaster under the guidance of Register Theory. For the unreasonable contents, he makes some correction in order to further optimize the translation of movie subtitles.

Twitter is an early microblog website in America, so experts had many researches on it at aboard. But because there are some differences in the focus of academic researches on microblog at home and abroad, foreign researchers are paying more attention to the relationship between microblog and marketing. In China, the researches focus on the characteristics of the language. Taking the language on Sina microblog as the research objects, He Qian (2011) and Zheng Yao (2013) do the exploratory analysis of microblog language from the perspective of sociolinguistics by using the Register Theory of Halliday's Systemic Functional Linguistics as the starting point of the research, and studies the 
essential characteristics of the microblog language in detail from three main aspects: field, tenor and mode. Wang Rui (2013) also makes a study of microblog with the selection of Yao Chen's microblogs as the focus of the argument. He briefly analyzes the celebrity's microblog interactions and the language used with her fans.

Although some scholars have studied microblog language from the perspective of Register, the study of celebrities' microblog language is still not enough. Nowadays, celebrities are public figures. Their microblogs effects the way people speak and act in reality, so it is necessary to conduct a deep-level and multi-angle study on celebrities' microblog language.

\section{HALLIDAY'S REGISTER THEORY}

In 1956, Ried proposed the concept of Register when studying bilingualism. And then Firth inherited the theory of studying language in language environment, and he pointed out when analyzing a typical language environment, we should focuses on the two factors: the relationship between the context itself, and the internal relationship in the language environment. As a very famous linguist in Systemic functional linguistics, Halliday conveyed the essence of the pervious theories to Systemic functional linguistics, and then he proposed the Register Theory. He actively developed and accepted the "situational context", and he thought that it is necessary to analyze the language in a certain environment $(\mathrm{Hu}, 2005)$.

Halliday holds that language has different variations in different contexts and it changes according to its function. He intends to explore the general principle governing the variation of language to help speakers and listeners to understand situational factors. Thus, he makes an endeavor to explore "what situational factors determine what linguistic features" (Halliday, 1978). Then he puts forward three variables which constitute Register - "the field of discourse", "the tenor of discourse" and "the mode of discourse". They influenced the elements -- "what" "how" and "who" in context, and thus make a difference in language use. These three variables will be discussed in detail to provide a foundation for Register analysis in this research.

\section{A. The Field of Discourse}

Field refers to "the institutional setting in which a piece of language occurs and embraces not only the subjects matter in hand but the whole activity of the speaker or participant in a setting" (Halliday, 1978, p. 33). In other words, the field means what is happening and the social action that is taking place. Most of the time the subject matter and topic are regarded as the field. However, the concept of field does not limit to subject matter and topic. It also involves the activities the participants taking part and the whole setting of relevant actions. It can be classified into two parts: the external world such as events, things, qualities, etc. and the internal world such as feelings, beliefs and thoughts, etc. Field can be divided into technical field and un-technical field. Technical field is often professional and formal, yet un-technical field can also be called daily field. Thus not only topics should be taken into consideration but also the whole on-going events. For example, when people are talking about gossips, the field is non-technical and the language is informal. It is usually about other's private lives often including unkind and untrue remakes and it usually happens between people with close relationship such as friends, classmates or relatives.

\section{B. The Tenor of Discourse}

Tenor is defined as the relationship between the participants. It refers to the subjects in communication, the nature, the status, the role of these subjects and reflects the degree of emotional charge in the communication process. It includes personal tenor and functional tenor. Thus social relationships of speakers should be focused on including both permanent relationship and contemporary relationship. The tenor of discourse corresponds to the interpersonal function. Halliday (1985) puts forward two aspects with regard to participant's role, respectively, "first-class social role" and "second-class social role". As for "first-class social role", it means stability and long-term relationship between participants. "Second-class social role" refers to a dynamic or temporary relationship. For instance, the chatting between teachers and students in class differs from the chatting when students visit teacher's home on Teachers' Day. Students-teacher relationship weakens when the situation changes, thus in this example tenor decides their way of talking. The relationship between participants depends on three aspects: status, affective involvement and contact. Status refers to the social position and other factors including gender, age, occupation, as well as wealth. As for power relation, it concerns whether the participants are equal in social status or not. The communication between employer and employee belongs to less equal power relation, whereas communication between classmates is equal power relation. The emotional involvement can be analyzed with the help of modal vocabulary, attitude words and taboo words, etc. It can be reflected by how much emotion and feelings are paid in this communication. For instance, lovers and families pay more love and affection than that of colleagues or classmates. Contact extent can be classified as frequent contact and occasional contact. If participants' contact is frequent, their language is free and casual. In this condition, their language is informal. On the contrary, if the contact is less frequent, communication tends to be prudent. To sum up, the relationship between participants in communication is of great importance and makes a big influence their language use.

\section{The Mode of Discourse}


Mode refers to "what kind of role the language plays" (Halliday, 1985, p. 38). To be specific, it indicates the channel, media and rhetorical ways of communication adopted. Halliday (1985) suggests that the mode of discourse can be analyzed from three perspectives including planning, feedback and media. As for planning, language can be either spontaneous or planned. Feedback can be either immediate like a phone call or delayed like a letter. Media can be classified as written form and oral form. Sometimes the form is between written and oral forms such as speech and news report. They are oral forms with formal written drafts. Instead, dictation is an informal form which is spoken to be written. Thus oral forms can be divided into preparing one and unprepared one. These three situational factors determine the register and thus influence the choice of language. Language with different registers has different words, phrases, and grammar features. For instance, communication in office between boss and employers is a context of situation. Field is the content in their conversation, most of the time work matters. Taboo or gossip rarely occurs in such situation. Tenor refers to the relation between boss and employers. Apparently, the boss's status is higher than employers' and thus has a powerful relationship. They have a certain social distance and thus cannot talk casually like relatives. Less affection is paid in this context of situation. The mode is often formal and can be either prepared or unprepared. The media can be written if someone makes notes at a meeting or oral in a seminar. At all events, the three situational factors determine the language features and influence language choices in office.

\section{AnAlysis of Celebrities’'Microblogs FROM Register}

The characteristics of linguistic variables of the celebrities' microblog language are different from the real world, but they are closely related to each other. For example, when expressing "a certain degree", we can choose to use the words “super”, “very” etc, but in celebrities' microblog language, the new expressions such as “敲...” “剧...” emerged. Why entertainment stars will choose these among many options? This chapter will specifically analyze the celebrities' microblogs from the three variables of Register and the impact of these three variables on celebrities' microblog language.

\section{A. The Characteristics of Celebrities' Microblogs in the Field of Discourse}

According to Halliday's Register Theory, the field of discourse studied in this paper refers to the topic of conversation and the venue. The influence of the field of discourse on celebrities' microblog language is mainly reflected in the celebrities' microblogs which are relative to hot events and mingled with foreign languages.

\section{Celebrities' Microblogs Relating to Hot Issues}

Different from communication of the real world, communication of the microblog is mainly spread through the form of text. Therefore, the interviewer has to abandon the general communicative premise in the contextual information, and uses different topics for language setting to enhance interaction. The language of the celebrities' microblogs is mainly based on the topic of the activities of the celebrities, because they want to gain public awareness considering the particularity of their profession. The influence of the topic on celebrities' microblog language is mainly reflected in the close connection between the buzzwords of the celebrities' microblogs and some events in the objective world or network culture, and using some words from hot issues or sensitive events to express their emotions and point of views.

Here are some examples to support the research.

The first one is the word “营业”, it means that the store is open for business, but the "business", as a new term in fans” circle, means that their idols have some work arrangements. On the current microblogs, the meaning of the word almost indicates that stars post some photos of themselves on sina microblog regularly or irregularly. Yang Zi typed the word “营业图” in her microblog and matched her own photos to narrow the distance between her and her fans. It shows that she has common topics with her fans. (See picture1 in appendix).

“哪吒” is a cartoon character. After the movie named “哪吒” was released, more and more people have been imitating his hairstyles. Xie Na used “哪吒娜” in her microblog which was related to “Happy Camp”. On the one hand, she used it to show her love to “哪吒”. On the other hand, she wanted to attract more attention to the show. (See picture 2 in appendix).

The word “打 call" derives from the culture of Japanese concerts, it means that the fans follow the rhythm of music and interact with performers on the stage by shouting and screaming according to regular patterns. For instance, Li Chen used the word “打 call" in his employer's official microblog for the propaganda of a movie to show his support.

(See picture3 in appendix)

\section{Massive use of Foreign Words in Celebrities' Microblogs}

Through microblog, netizens can jump out of the limitation of time, space and region to carry out communication, while celebrities' microblogs mainly influence the public in the mingle use of dialects and foreign languages. In the celebrities' microblogs, they use some foreign words intentionally or unintentionally to meet the requirements of pursuing something new, changeable, and different in communication of microblogs, and make it closer between the stars and the audience in everywhere. The foreign words in the celebrities' microblogs have different language sources, but most of them are mixed with English. Here are some examples.

In one of Zhang Yixing's microblog, he wrote “好久没有 freestyle 了”. “Freestyle”, an English vocabulary, generally refers to impromptu casual play. Freestyle in hip-hop rap is refers to impromptu rap. It becomes popular around the 
network because of Wu Yifan's frequent mentions of this word in "hip-hop in China". Here, Zhang Yixing used this word to show his professional in dancing and his closely connection with the popular things. (See picture4 in appendix).

The word "Get" comes from English and means getting some kind of things or skills. Due to the particularity of the celebrities' profession, their microblogs' contents are often related to product promotion. Therefore, the word "get" is mentioned in most of their microblogs, which is used to promote products. They write "get" before the name of the products or the word “同款”, which aims at appealing their fans to trust and purchase the products, such as Yang Mi's microblog, “get 我的同款”, “get 钙尔奇牛乳钙软糖”. (See picture5.6 in appendix) Wang Yibo’s microblog, “get 我 的同款美肌秘籍”（See picture7 in appendix） and so on.

At the same time of reposting Wang Ziyi's music promote microblog, Wang Linkai wrote several words “继续加油 bro". The word "bro" is the abbreviation of English word "brother", it was made an instant hit because Wang Ziyi always use it in a program named "Idol Producer". Here, Wang Linkai used this term to show that he is not only close to Wang Ziyi, but also follows the trend of the Internet.(see picture 8 in appendix)

\section{B. The Characteristics of the Celebrities'Microblogs in the Tenor of Discourse}

The tenor mainly refers to the formality of the language, which is determined by the identity of the participants and their role relationship. The two sides' microblog communication is in a peer-to-peer scenario, and equality is its most important feature. Therefore, the language of celebrities' microblogs is relative casual and oral that reflects the diverse personal speech style. The arbitrariness and equality of microblog communication determines the informality of tenor. The audiences of the celebrities' microblog are grouped into two categories: stars or between stars and their friends and relatives (regular and emotional input on contact); between stars and the public (infrequent contacted and not invested emotional input). Languages of celebrities' microblogs are different for the two groups because of the different emotions and differences in contact.

\section{The Characteristics of the Celebrities' Microblogs for Familiar People}

Because of the informality of the tenor, the celebrities often use modals and nicknames in their microblogs for the familiar group to show their emotions and intimacy between them. At the same time, due to the particularity of the celebrities' profession, the modals that they used are often given special roles, such as enhanced, ridiculed, praised, or affirmed. In order to attract public attention, modals in the celebrities' microblogs are mostly followed the sentence, such as “嘛, 哈, 哒, 吧, 嗯, 哦, ”etc. Here are some examples, Yang Zi said “涛姐么么哒”in her microblog. Here, she used “么么哒” to show that they are very good friends, and it can makes people think that she is cute.(See picture 9 in appendix) Xie Na also likes to use modals in her microblogs. She said “那么我和何老师隔空相聚周五啦哇哈哈哈 哈哈哈”,in her microblog one day. Here, she used five “哈” to show that she was very happy to meet He Jiong, and these modals also shows that she is outgoing. And in Du Haitao's microblog(see picture 10 in appendix), he said “哇封面好 多喜欢的人啊”. Here, he used “啊” to express his sigh. And it shows that many people on the cover are his friends, and they are close to each other.(see picture 11 in appendix) In Yuan Shanshan's microblog, she said “吃饭你来吗?”, here, the word “吗” is playing the same role as it used in the daily language, and it showed that she was nervous.(see picture 12 in appendix)

\section{The Characteristics of Celebrities' Microblogs for Public}

Celebrities are only communicating with their fans on the online platform-Sina microblog, their contact is almost zero, and there are on emotional investment.

Under this premise, celebrities must manage their own work or their own image to ensure the growth or maintenance of the number of their fans (embodiment of popularity). Celebrities often use greetings and chilling words in their microblogs to narrow the distance between them and the public, and maintain a close relationship with the public. Such as “大家好”, “早上好”, “晚安”, “节日快乐”,etc

There are many stars often write very simple words "晚安” that means Good night in their microblogs. For example, In Xie Na’s microblog, “眼里有光晚安”, and He Jiong’s microblog “晚安”.They often use these daily languages to make public think they are very kind.(see picture 13.14 in appendix).There are also some stars uses the Greetings, such as “大家好”, “你好” to introduce the new character that they are play. Such as Li Xian’s microblog, “大家好, 我是白十 三”, Zhao Lusi’s microblog, “大家好, 我是耳朵也是云裳”, and Yang Zi’s microblog, “你好, 这里是鱿小鱼请多关 照”.(See picture 15,16,17 in appendix)

\section{The Characteristics of Celebrities'Microblogs in the Mode of Discourse}

The mode of discourse can be divided into two categories: spoken and written. Celebrities' microblog is an interpersonal communication realized by computer-aided, and symbol is its main expressive form. But it is totally different from chatting in the traditional sense. Here, spoken and written language can be organically integrated to form a unique language, that is, between written communication and oral communication. Because the contents of celebrities' microblogs are diverse, the Mode of celebrities' microblogs can be switched between the two categories, and they often presented in words, emotions, audios and so on.

1. The Arbitrariness of the Celebrities' Microblogs 
The arbitrariness of celebrities' microblogs is reflected in mixed use of Chinese, foreign languages, dialects, expressions, letters and mathematics, etc. It usually embodied in the form of doping, simplification, and near-tone. Here are some examples. In Sha Yi’s microblog, he said “英子,开门, 呆地”, here “呆地” is from English word “Daddy”, it was used to make the sentence more funny and colloquial. In Xie Na's microblog, she said “这张给造谣者, piu piu”. This sentence consists of Chinese and onomatopoeia.It can strongly show her real feeling and the meaning she wanted to say. In He Jiong’s microblog, he said “今天谁是你的蓝朋友”, Here, the meaning of “蓝朋友” is boyfriend, he used synonyms to create a relaxed atmosphere. In Wei Daxun's microblog, he said “照骗”, this word is the euphony of “照 片”, the meaning of “照片” is photo, but now the word “照骗” means that the photo doesn't match with himself, and it's consistent with the funny features that he showed the public.(See picture 18,19,20,21 in appendix)

\section{The Infectivity of Celebrities' Microblogs}

In the real-world, the communicative subjects can adjust the progress of the discourse by the facial expressions, body language and voice intonation. And from these parts, communicative subjects can know others' mental activities. However, in order to get proper communicative affects in the microblogs' communication, celebrities need to use auxiliary means to make up for the lack of communication in order to get proper communicative affects, such as repeated punctuation, a lot of dynamic emotions, a lot of pictures, etc. Here are some examples. In Yang Zi's microblog, she said “就在明天啦！！！！！！冲啊！！”, she used multiple exclamation points to strengthen the tone of the words and make them more vivid. (See picture 22). Because Sina microblog's emoticons have dynamic effects which make language communication more vivid, so celebrities' microblogs used a lot of emoticons. Here are some examples, in Jackson Yee's microblog, he said“一起大步向前走+emoticon”, and in Deng Lun's microblog, he said “永远支持你 +emoticon".(See picture23, 24 in appendix). Because of the text restrictions of Sina microblog, celebrities express their ideas and feelings through some small videos, pictures, etc. For example, in picture 25, Zhang Yixing only wrote some words from his new lyric, and put the mv with these words together. In this way, He directly recommended his song to the public. (See picture25 in appendix)

\section{CONCLUSION}

The field of celebrities' microblogs is cross-geographical because of the contextual factors and plentiful topics. It mainly showed by the mixed use of a large number of foreign languages and the words from hot issues. Because everyone is equal in Sina microblog, the tenor of the celebrities' microblogs is mainly influenced by contact and emotion. The characteristics of celebrities' microblogs are the high-frequency uses of modals and greetings. Dominated by the expression of symbols and words, the celebrities' microblogs are used informal spoken and written languages as a discourse mode. Influenced by the mode of the discourse, the characteristics of the celebrities' microblogs are arbitrariness and infectivity. All in all, according to these characteristics of the celebrities' microblogs, the majority of netizens should rationally treat the celebrities' microblogs, and do not blindly follow the trend.

\section{APPENDIX}

1.

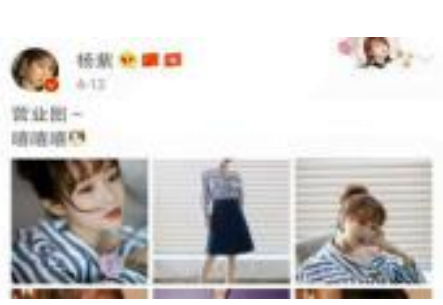

4.

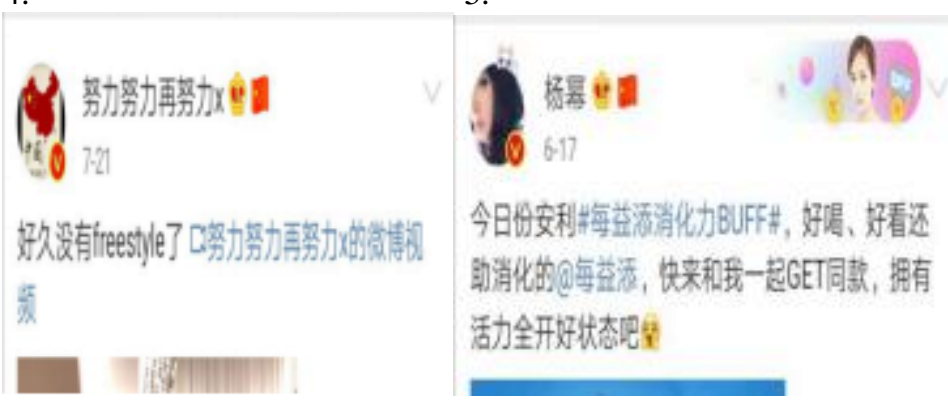

2.

5.
3.
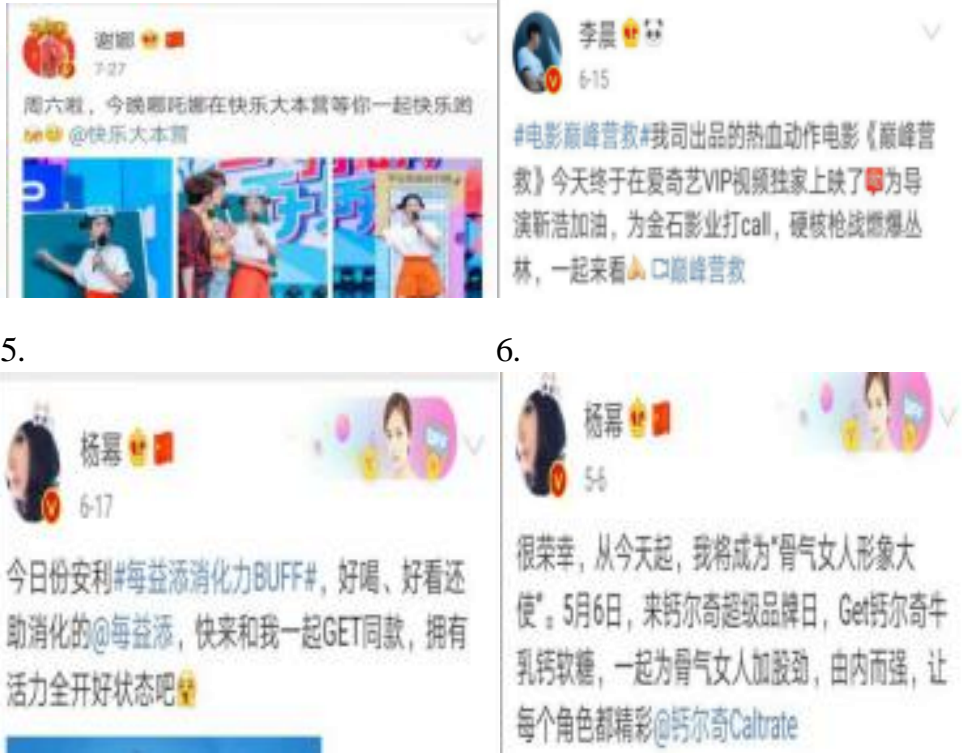
7.

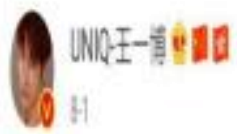

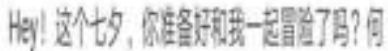

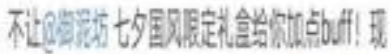

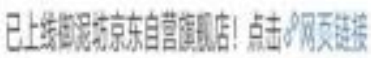

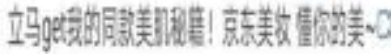

10.

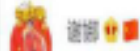

do 43 estit

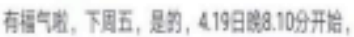

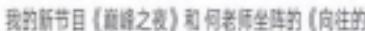

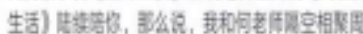

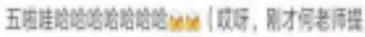

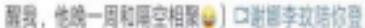
上 (萑结之就)

13.

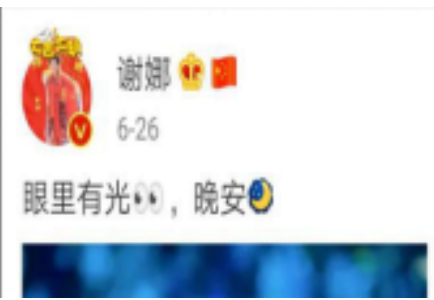

16.

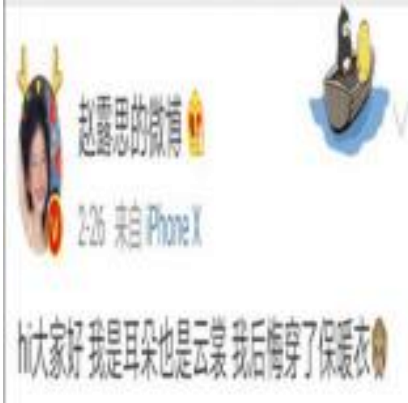

14.

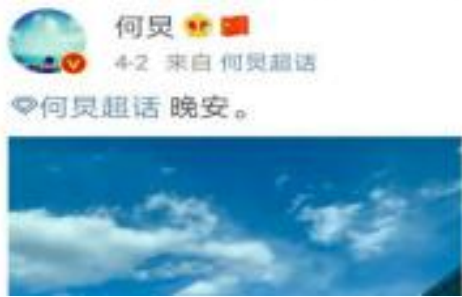

17.

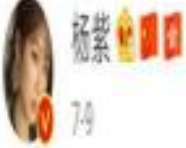

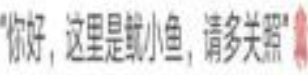

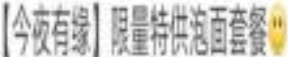

9.

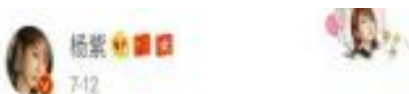

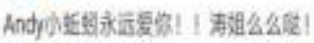

Bixiftamis:

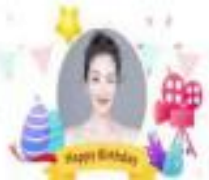

12.

(당

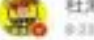

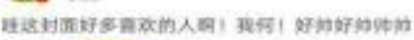
n! 11 eve

고ำ

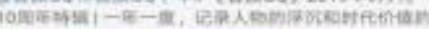
git.

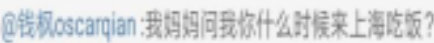

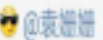

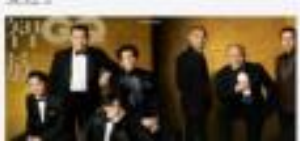

15.

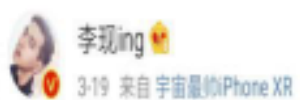

大家好，我是白十三。今天是好好”上学“的一天，

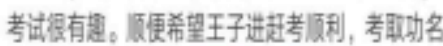
以后不要忘了我。电影春江花腋、请期我一起管 促能。

18.

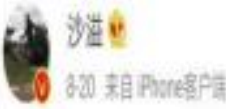

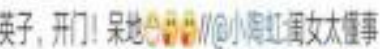

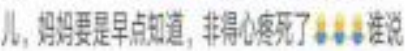

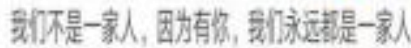

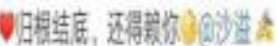

19.

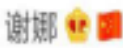

8-13

这张给造谣者, piu, piu.....

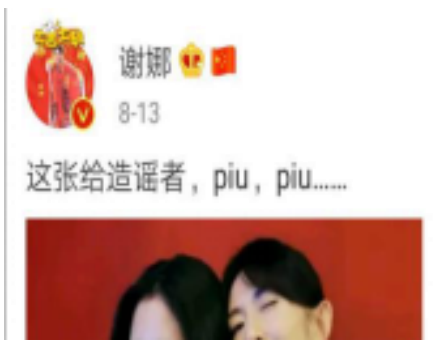

20.

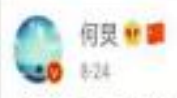

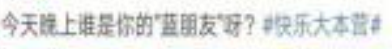

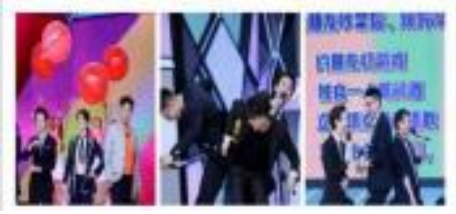

21.

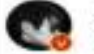

ext部 $* \mathrm{En}$

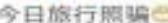

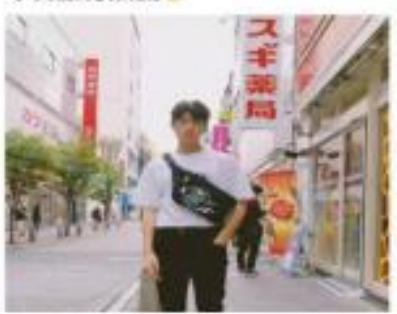


22.

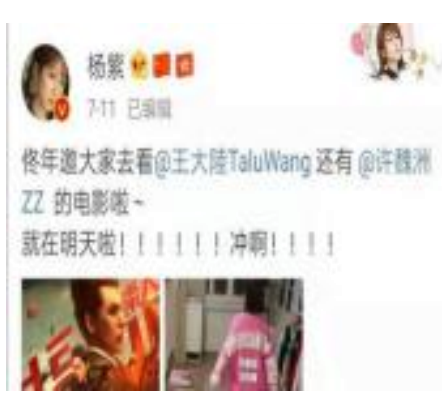

23.

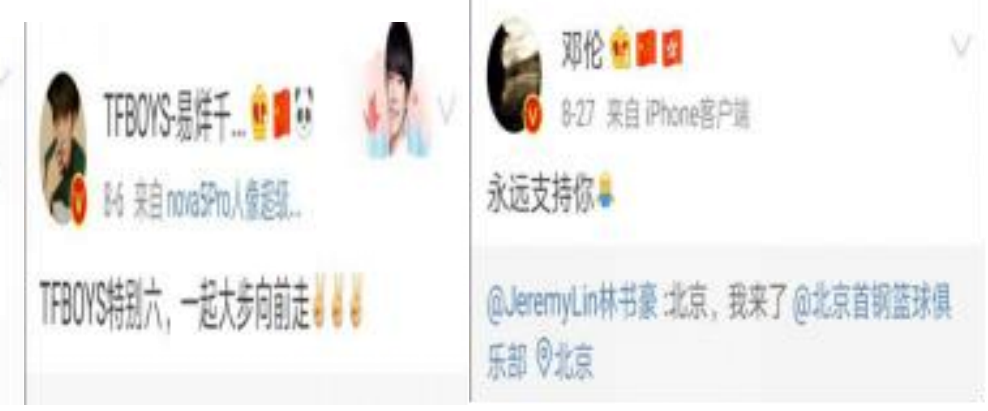

25.

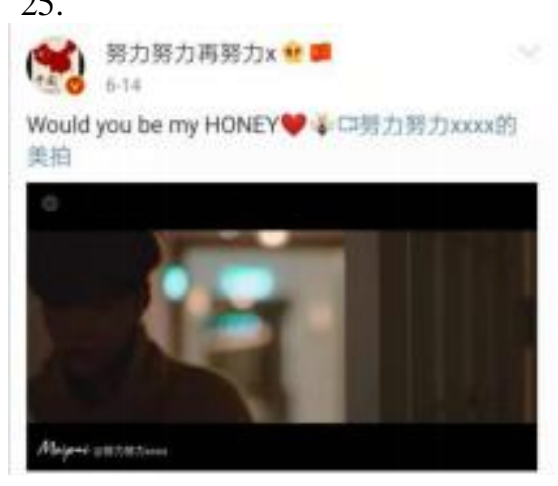

REFERENCES

[1] Chen Xinjie. (2017). A Study of Subtitle Translations of Empresses in the Palace from the Perspective of the Register Theory. M.A. Thesis. Beijing Jiaotong University.

[2] Halliday, M.A.K. (1978). Language as Social Semiotic: The Social Interpretation of Language and Meaning. London: Edward Arnold, 32, 33.

[3] Halliday, M.A.K. \& Hasan. (1985). Language, Text and Context: Aspect of Language in a Social Semiotic Perspective. Geelong: Deakin University Press, 38.

[4] He Qian. (2011). A Study of Microblog Language from Perspective of Register Theory. M.A. Thesis. Taiyuan University of Technology.

[5] Hu Zhuanglin, Zhu Yongsheng, Zhang Delu. (2005). An Introduction to Systemic Functional Linguistics. Beijing: Peking University Press, 125.

[6] Li Junfeng. (2017). On Film Subtitle Translation of the Grandmaster from the Perspective of Register Theory. M.A. Thesis. Xi' an International Studies University.

[7] Sun Yingping. (2019). A Study on Verbal Humor in The Big Bang Theory from the Perspective of the Register Theory. M.A. Thesis. Inner Mongolia Normal University.

[8] Wang Chaojing. (2017). A Research on the Humor of Situation Comedies in Light of Register Theory -A case Study of Friends. M.A. Thesis. North University of China.

[9] Wang Rui. (2013). A Research on Celebrities' Microblogs- A case study of Yao Chen' microblogs. M.A. Thesis. Guangzhou University.

Qixia Liang was born in Shanxi, China in 1996. She received her bachelor's degree in English Education from Lvliang University, China in 2017.

She is currently a graduate student in the School of Foreign Languages, Shanxi Normal University, Shanxi, China. Her research interests include pragmatics and applied linguistics. 